\title{
PENGUKURAN KEPUASAN PELANGGAN MENGGUNAKAN SERVQUAL DI SPINELLI COFFEE GANDARIA
}

\author{
Nami Fitricia Pasaribu \\ Hotel Management, Faculty of Economics and Communication, BINUS University \\ Jln. K. H. Syahdan No. 9, Palmerah, Jakarta Barat 11480 \\ tricia_indigo03@yahoo.com
}

\begin{abstract}
Customers satisfaction to service and or tangible products provide by coffee shop could be a distinctive phenomenon to a company. To give in-depth insight for this issue, the study and SERVQUAL approach was valued to help Spinelli Coffee to give their best service. Using interview and questtionaire, it is hoped to bridge customers needs to providers. In a hope of customers expectation and perceive synchronization onto the service. Result of innovative output such as on-line feedback from customers to the company to acknowledge market demand was an intetion from this study.
\end{abstract}

Keywords: Servqual, coffee shop, satisfaction, best service, feedback

\begin{abstract}
ABSTRAK
Kepuasan pelanggan, terhadap produk jasa maupun barang yang dihasilkan sebuah coffee shop dapat menjadi sebuah fenomena tersendiri bagi perusahaan. Sehingga guna memberikan sebuah pengkajian untuk hal ini maka pendekatan metode SERVQUAL dinilai akan membantu Spinelli Coffee untuk bisa memberikan pelayanan terbaik. Dengan metodologi wawancara dan kuesioner, diharapkan dapat menjembatani keinginan pelanggan dan penyedia barang dan jasa. Sehingga terjadi sebuah sinkronisasi dari servis yang diberi dan penerimaan dari pelanggan. Hasil akan keluaran baru berupa pengisian on-line dari customer ke perusahaan guna mengetahui demand pasar adalah hasil akhir yang ingin dicapai.
\end{abstract}

Kata kunci: Servqual, coffee shop, kepuasan, pelayanan prima, feedback 


\section{PENDAHULUAN}

Artikel ini dibuat untuk mempelajari hal yang menjadi sebuah hubungan antara kepuasan pelanggan dengan terpenuhinya kepuasan kerja dari karyawan di sebuah perusahaan. Banyak opini yang dengan lantang menyuarakan eratnya kaitan antara keduanya. Maka dengan ketertarikan yang sama, studi ini dilakukan. Pemilihan coffee shop di sini dikarenakan sebuah fenomena dari bisnis retail yang sedang berkembang. Sementara itu, alasan bisnis ini dapat unggul di antara kompetitornya adalah latar belakang ditulisnya artikel ini.

Merujuk kepada teori A service is an activity or series of activities of more or less intangible nature that normally, but not necessarily, take place in interactions between customer and service employees and/ or physical resources or goods and/ or systems of the service provider, which are provided as solutions to customer problems (Grönroos, 1990:27), maka ide terbentuk untuk menilik lebih dalam.

Di Indonesia kompetisi di industri gerai kopi secara retail, dimulai pada 2000. Berkembang hingga saat ini dan tiap brand ingin memiliki distinctive service untuk pelanggannya, selain produk minuman kopi yang dihasilkan. Pelanggan memiliki pandangan, bahwa yang diterima atau dialami pada saat proses terjadinya layanan adalah nilai dari servis itu sendiri. Dan penilaian terpenuhinya kepuasan pelanggan terhadap jasa yang diberikan berada pada time frame tersebut. Ghobadian, Speller and Jones (1994) mengemukakan: “customers' expectations, service delivery process and service outcome have an impact on perceived service quality". Sementara Yoo and Park (2007) mengatakan: "found that employees, as an integral part of the service process, are a critical element in enhancing perceived service quality".

\section{Latar Belakang}

Kepuasan pelanggan menurut Edvardsson (2005) pointed out that service quality perceptions are formed during the production, delivery and consumption process. Dengan terjemahan bebas, persepsi layanan berkualitas terbentuk pada produksi, penyampaian dan proses konsumsi. Kepuasan tersebut akan memiliki bentukan yang berbeda dari setiap persepsi setiap orang, dengan ini sebuah coffee shop memerlukan suatu standar operasional guna memberikan framework bagi karyawannya dengan menggunakan Standard Operation Procedure dan memberikan sebuah keluaran servis yang seragam bagi pelanggannya. Pada bisnis retail hal ini adalah sebuah challenge. Namun tidak dapat dipungkiri kebutuhan dan keinginan pelanggan perindividu seyogyanya dapat dipenuhi oleh tiap karyawan.

\section{Pengertian dan ciri-ciri Coffee Shop}

Pengertian coffee shop menurut Metelka yang dalam Sugiarto \& Sulartiningrum (1996): "Coffee Shop adalah suatu usaha di bidang makanan yang dikelola secara komersial yang menawarkan kepada tamu makanan atau makanan kecil, dengan pelayanan dalam suasana tidak formal tanpa diikuti aturan service yang baku (sebagaimana executive dining room), jenis-jenis harganya lebih murah.”

Adapun ciri-ciri dari coffee shop, menurut Soekresno (2000:18-19) adalah sebagai berikut: harga makanan dan minuman relatif murah, penerimaan pelanggan tanpa sistem pemesanan tempat, para pelanggan tidak terikat untuk menggunakan pakaian formal, sistem penyajian makanan dan minuman yang dipakai American Service/ ready plate bahkan self service ataupun counter service, tidak menyediakan musik hidup, penataan meja dan bangku cukup rapat antara satu dengan yang lain, daftar menu tidak dipresentasikan kepada tamu/ pelanggan. Namun dipasang di counter atau langsung disetiap meja makan agar mempercepat proses pelayanan, menu yang disediakan sangat terbatas dan membatasi menu-menu yang cepat dimasak, jumlah tenaga service relative sedikit dengan standar 
kebutuhan. Namun karena kompetisi yang ketat, sebuah coffee shop saat ini mulai menyediakan musik hidup untuk variasi dalam entertainment.

\section{Kepuasan Konsumen}

Zeithamal (2004) merumuskan kepuasan konsumen sebagai "costomer's evaluation of a product or service in terms of whether that product or service has met their needs and expectation". Setelah konsumen mendapatkan barang ataupun jasa yang diberikan maka terjadilah evaluasi, dan akhirnya memutuskan apakah produk tersebut telah mencapai kebutuhan dan ekspektasi konsumen. Apabila jawaban yang dimiliki oleh pelanggan adalah ya, maka terbentuklah kepuasan tersebut. Bagi pemberi pelayanan jasa, hal ini sangat penting. Dengan adanya kepuasan pada pelanggan maka diharapkan terbentuknya kesetiaan pelanggan dan repeat consume.

Apabila kepuasan pelanggan didapat, keinginan yang ingin dicapai oleh penyedia barang dan jasa adalah input positif dari konsumen, dan melahirkan kesediaan untuk rekomendasi atau sering disebut juga willingness to reccomend. Suatu pencapaian tinggi untuk sebuah penyedia barang dan jasa.

\section{Tipe Konsumen}

Untuk mengenali siapakah pelanggan kita, maka diperlukan suatu kajian target konsumen yang akan dituju. Disamping itu, perusahaan perlu menetapkan pasar apa yang menjadi tujuan. Berikut ini adalah pemisahan tipe konsumen dalam dua golongan besar: tipe konsumen Up-market (empat tipe) dan tipe konsumen Down-market (tujuh tipe).

Tipe up-market dapat dijumpai di tempat yang memiliki pelayanan yang "lebih baik" dalam hal ini dicontohkan seperti hotel berbintang dan restoran mewah. Memiliki pekerjaan yang berpenghasilan tinggi serta tidak memiliki banyak waktu luang. Dalam tipe ini ada empat sub-tipe di dalamnya yaitu: masyarakat yang mampu dan menyukai produk Horeka, dan bersedia membayar mahal; masyarakat yang mampu dan sedang berlibur; manajer dan direktur yang sedang mengadakan perjalanan dinas; peserta konggres

Tipe down-market dapat ditemukan tujuh tipe konsumen sebagai berikut: pengunjung kafe yang kerap mengunjungi kafe populer; masyarakat umum sederhana yang suka keluar makan, namun harus berhemat; generasi muda yang sering keluar pada akhir minggu dengan kelompoknya namun tidak memiliki dana yang banyak, tetapi merupakan konsumen yang antusias; wisatawan umum sederhana yang pergi berkelompok dan tidak memilik dana yang berlebih; keluarga sederhana yang sedang berlibur; pelaku bisnis menengah yang sedang mengadakan perjalanan dinas; pegawai kantor yang memerlukan makan siang.

Dengan mengenal tipe-tipe konsumen diharapkan sebuah coffee shop dapat membuat penelitian untuk range harga dan tingkat pelayanan yang dibutuhkan oleh tiap konsumennya. Dan dapat merumuskan pula kisaran harga atau paket yang mencakup tipe konsumen.

\section{Hospitality Market through The Customer's Eye}

Ada dua cara untuk mengamati usaha hotel, restoran, dan kafe (HoReKa) yaitu dari sudut pandang pengusaha atau manajer HoreKa dan dari sudut pandang konsumen/tamu/pengunjung. Pengamatan dari sudut pandang pengusaha sudah dilakukan sejak cabang usaha Horeka berkembang, namun cara pandang ini dipandang tidak efektif lagi dalam mengembangkan kepuasan pelanggan. Sedangkan pengamatan dari sudut pelanggan merupakan pendekatan pelayanan jasa yang baru dan merupakan kunci sukses pemasaran Horeka. Hal ini menjadi pendahuluan oleh Rio Budi Prasadja dalam bukunya Psikologi Pelayanan Jasa Hotel, Restoran dan Kafe. 
Dan apabila kita menilik lebih dalam sudut pandang pelanggan maka kita perlu mengenali siapa pelanggan kita. Dengan mempelajari demografi dari pelanggan kita; Siapa konsumen kita, apa yang mereka lakukan, bagaimana opini mereka tentang perusahaan dan bagaimana cara melayani mereka (hospitality). Perusahaan yang berorientasi kepada pelanggan selalu mendapatkan posisi yang kuat. Karena pelanggan mereka akan mengetahui apa yang akan mereka dapatkan dan sesuai dengan apa yang mereka harapkan.

\section{Distinctive Characteristic of Service Operations}

Dalam usaha penyediaan jasa, ciri khas atau sesuatu yang berbeda merupakan sesuatu yang akan memperkuat citra (image). Dalam usaha jasa, hal ini diberikan oleh pelanggan sebagai input dan oleh karyawan sebagai sumber daya, untuk berfungsinya dua hal tersebut maka sistem yang dimiliki harus berinteraksi dengan pelanggan sebagai pengambil bagian dalam proses terjadinya pelayanan tersebut. Hadirnya pelanggan dalam proses ini dapat menjadi penggambaran bahwa perusahaan tersebut memiliki kepercayaan diri yang tinggi dan berusaha senantiasa mengembangkan diri. Dengan konsiderasi merealisasikan peran pelanggan dalam proses terjadinya excellence service.

\section{Konsep Kualitas Layanan (Service Quality)}

Dalam kualitas layanan ada beberapa dimensi yang perlu diperhatikan, yaitu (Parasuraman, Berry \& Zeithaml dalam Tjiptono, 2004:70): bentuk fisik atau yang berwujud (tangibles) adalah kondisi yang ada dalam memberikan pelayanan meliputi kualitas fisik, perlengkapan, pegawai dan sarana komunikasi; keandalan (reliability) adalah kemampuan memberikan pelayanan yang dijanjikan dengan segera, akurat dan memuaskan; daya tanggap (responsiveness) adalah keinginan para staf untuk membantu pelanggan dan memberikan pelayanan yang tanggap; jaminan (assurance), mencakup pengetahuan , kemampuan, kesopanan dan sifat yang dapat dipercaya. Yang memiliki staf bebas dari bahaya, resiko dan keragu-raguan; Empati (Emphaty), meliputi kemudahan dalam melakukan hubungan, komunikasi yang baik, perhatian pribadi dan memahami kebutuhan para pelanggan.

Dalam usaha jasa, kualitas terjadi pada saat proses penyampaian pelayanan tersebut dilakukan. Setiap interaksi dengan konsumen adalah saat kebenaran (moment of truth) dari janji kualitas pelayanan prima. Kepuasan pelanggan dapat didefinisikan dengan persepsi yang diinginkan bertemu dengan ekspektasi pelanggan. Hal tersebut diilustrasikan pada gambar 1 berikut ini.

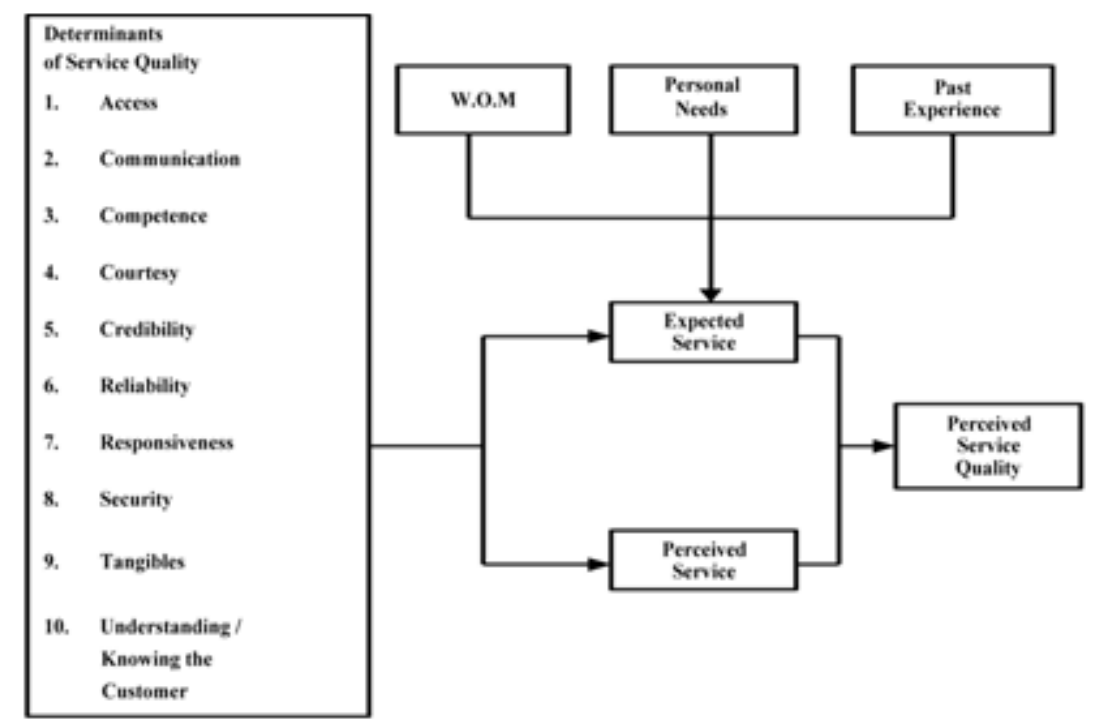

Gambar 1 Persepsi Pelanggan terhadap Kualitas Pelayanan Sumber: Zeithaml 


\section{Kesenjangan dalam Layanan Berkualitas}

Dalam proses terjadinya layanan, akan ada kesenjangan yang terjadi. Zeithaml et. al, membuat gambaran sebagai berikut.

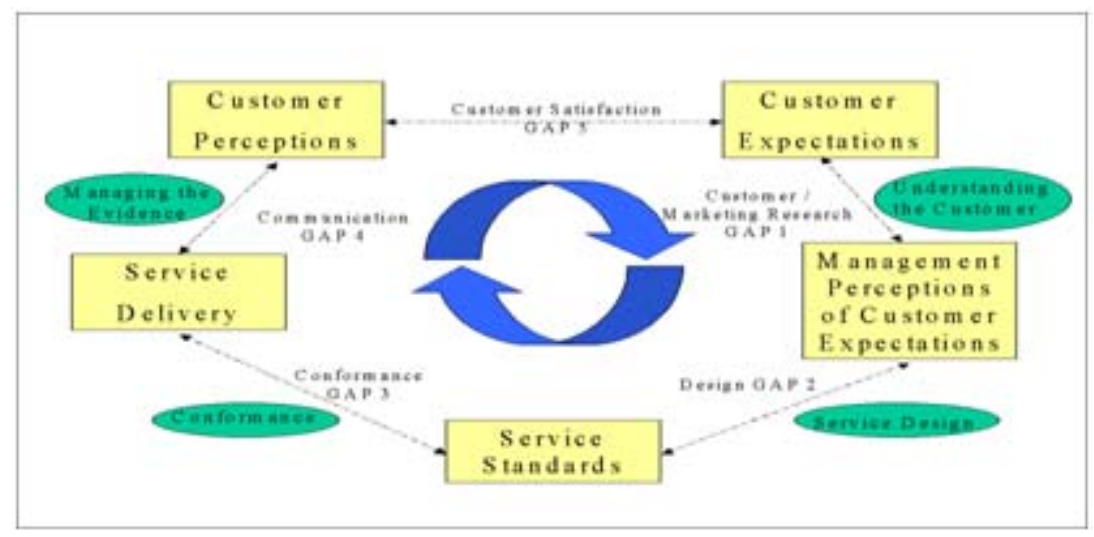

Gambar 2 Service Quality Gap Model

Gap 1 terjadi dari pihak manajemen yang kurang memahami bagaimana pelanggan memformulasikan ekspektasi mereka terhadap perusahaan (karena iklan, pengalaman pelanggan sebelumnya, pembahasan dengan teman - teman pelanggan). Gap 2 terjadi karena kurangnya komitmen dari manajemen terhadap Service Quality. Dengan menciptakan tujuan dan standar dalam penyampaian pelayanan diharapkan dapat menanggulangi kesenjangan ini. Gap 3 dapat terjadi untuk beberapa hal, dan berhubungan erat dengan sumber daya manusia; kurangnya kerjasama, seleksi karyawan yang buruk, training karyawan yang tidak memadai dan perencanaan frame work yang tidak baik. Yang mengakibatkan ketidaksesuaian atas standard pelayanan yang seharusnya diberikan. Gap 4 terjadi apabila terdapat pertentangan antara service yang diberikan dengan komunikasi eksternal yang diberikan kepada pelanggan, biasanya dikarenakan oleh janji yang terlalu dibesar-besarkan dan atau informasi yang kurang memadai. Gap 5 terjadi saat persepsi pelanggan dan ekspektasinya tidak sejalan. Yang mengakibatkan ketidakpuasan.

\section{METODE PENELITIAN}

Metode yang dipakai untuk mengukur adalah menyebarkan kuesioner. Dan format kuesioner diambil dari pegukuran dari Parasuraman et. al. Berikut ini adalah langkah-langkah dan instrumen yang dipakai.

\section{Steps to Obtain Unweighted Servqual Score}

Step 1; select a Coffee Shop the service quality of which you want to assess. Using the SERVQUAL instrument, first obtain the score for each of the 22 expectation questions. Next, obtain a core for each of the perception questions. Calculate the Gap Score each of the statements (Gap Score $=$ Perception - Expectation).

Step 2; obtain an average Gap Score for each dimension by assessing the Gap Scores for each of the statements that constitute the dimension and dividing the sum by the number of statements making up the dimension. 
Step 3; in table 1 transfer the average dimension SERVQUAL scores (for all five dimensions) from the SERVQUAL instrument. Sum up the scores and divide it by five to obtain the unweighted measure of service quality.

\section{Steps To Obtain The Weighted Servqual Score}

Step 1; in table 2 calculate the importance weights for each of the five dimensions constituting the Servqual scale. The instructions are provided along with the table.

Step 2; in Table 3 enter the average Servqual score for each dimension (from table 1) and the importance weight for each dimension (from table 2). Then multiply the average score for each dimension with its importance weight.

Step 3; add the weighted SERVQUAL scores for each dimension to obtain the overall weighted SERVQUAL score.

\section{HASIL DAN PEMBAHASAN}

\section{EXPECTATIONS}

This survey deals with your opinions of Coffee Shop. Please show the extent to which you think banks should posses the following features. What we are interested in here is a number that best shows your expectations about institutions offering Coffee Shop services

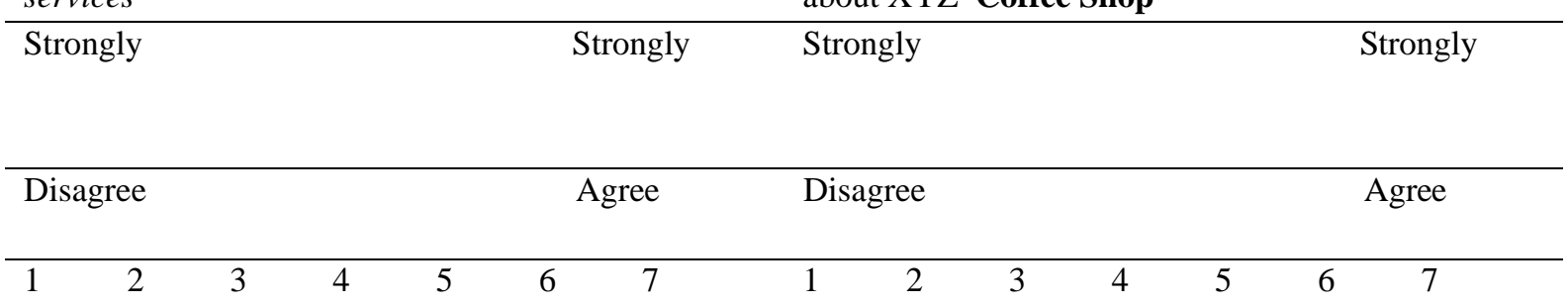

\section{PERCEPTIONS}

The following statements relate to your feelings about the particular Coffee Shop XYZ you chose. Please show the extent to which you believe XYZ has the feature described in the statement. Here, we are interested in a number that shows your perceptions about XYZ Coffee Shop

Strongly

\section{Tangibles}

E1. Excellent Coffee Shop companies will have modern looking equipment.

E2. The physical facilities at excellent coffee shop will be visually appealing.

E3. Employees at excellent Coffee Shop will be neat appearing.

E4. Materials associated with the service (such as pamphlets or statements) will be visually appealing at an excellent Coffee Shop.

\section{Tangibles}

P1. XYZ Coffee Shop has modern looking
equipment.

P2. XYZ Coffee Shop physical facilities are visually appealing.

P3. XYZ Coffee Shop reception desk employees are neat appearing.

P4. Materials associated with the service (such as pamphlets or statements) are visually appealing at XYZ Coffee Shop

\section{Reliability}

Reliability

E5. When excellent Coffee Shop promise to do P5. When XYZ Coffee Shop promises to do something by a certain time, they do. something by a certain time, it does so.

E6. When a customer has a problem, excellent Coffee P6. When you have a problem, XYZ Coffee Shop Shop will show a sincere interest in solving it. shows a sincere interest in solving it.

E7. Excellent Coffee Shop will perform the service P7. XYZ Coffee Shop performs the service right the right the first time. first time. 


\begin{tabular}{ll}
\hline $\begin{array}{l}\text { E8. Excellent Coffee Shop will provide the service at } \\
\text { the time they promise to do so. }\end{array}$ & $\begin{array}{l}\text { P8. XYZ Coffee Shop provides its service at the time } \\
\text { it promises to do so. }\end{array}$ \\
\hline $\begin{array}{l}\text { E9. Excellent Coffee Shop will insist on error free } \\
\text { records }\end{array}$ & P9. XYZ Coffee Shop insists on error free records
\end{tabular}

\begin{tabular}{ll}
\hline \multicolumn{1}{c}{ Assurance } & \multicolumn{1}{c}{ Assurance } \\
\hline $\begin{array}{l}\text { E14. The behavior of employees in excellent Coffee } \\
\text { Shop will instill confidence in customers. }\end{array}$ & $\begin{array}{l}\text { P14. The behavior of employees in XYZ Coffee } \\
\text { Shop instills confidence in you. }\end{array}$ \\
\hline $\begin{array}{l}\text { E15. Customers of excellent Coffee Shop will feel } \\
\text { safe in transactions. }\end{array}$ & $\begin{array}{l}\text { P15. You feel safe in your transactions with XYZ } \\
\text { Coffee Shop. }\end{array}$ \\
\hline $\begin{array}{l}\text { E16. Employees of excellent Coffee Shop will be } \\
\text { consistently courteous with customers. }\end{array}$ & $\begin{array}{l}\text { P16. Employees in XYZ Coffee Shop area } \\
\text { consistently courteous with you. }\end{array}$ \\
\hline $\begin{array}{l}\text { E17. Employees of excellent Coffee Shop will have } \\
\text { the knowledge to answer customers' questions. }\end{array}$ & $\begin{array}{l}\text { P17. Employees in XYZ Coffee Shop have the } \\
\text { knowledge to answer your questions. }\end{array}$ \\
\hline
\end{tabular}

\begin{tabular}{lll}
\hline \multicolumn{1}{c}{ Empathy } & \multicolumn{3}{c}{ Empathy } \\
\hline $\begin{array}{l}\text { E18. Excellent Coffee Shop will give customers } \\
\text { individual attention. }\end{array}$ & $\begin{array}{l}\text { P18. XYZ Coffee Shop gives you individual } \\
\text { attention. }\end{array}$ & $\begin{array}{l}\text { P19. XYZ Coffee Shop has operating hours } \\
\text { convenient to all its customers. }\end{array}$ \\
\hline $\begin{array}{l}\text { E19. Excellent Coffee Shop will have operating } \\
\text { hours convenient to all their customers. }\end{array}$ & $\begin{array}{l}\text { P20. XYZ Coffee Shop has employees who give you } \\
\text { personal attention. }\end{array}$ \\
\hline $\begin{array}{l}\text { E20. Excellent Coffee Shop will have employees } \\
\text { who give customers personal attention. }\end{array}$ & P21. XYZ Coffee Shop has your best interest at heart. \\
\hline $\begin{array}{l}\text { E21. Excellent Coffee Shop will have their } \\
\text { customer's best interests at heart. }\end{array}$ & $\begin{array}{l}\text { P22. The employees of XYZ Coffee Shop understand } \\
\begin{array}{l}\text { E22. The employees of excellent Coffee Shop will } \\
\text { understand the specific needs of their customers. }\end{array}\end{array}$ \\
\hline
\end{tabular}

THE SERVQUAL INSTRUMENT

Tabel 1 Calculations to Obtain Unweighted Servqual Score

\begin{tabular}{l}
\hline Average Tangible SERVQUAL score \\
\hline Average Reliability SERVQUAL score \\
\hline Average Responsiveness SERVQUAL score \\
\hline Average Assurance SERVQUAL score \\
\hline Average Empathy SERVQUAL score \\
\hline TOTAL \\
\hline AVERAGE (= Total / 5) UNWEIGHTED SERVQUAL SCORE \\
\hline
\end{tabular}

Tabel 2 Servqual Importance Weight

\begin{tabular}{l}
\hline $\begin{array}{l}\text { 1. The appearance of the Coffee Shop physical facilities, equipment, personnel, } \\
\text { and communication materials. }\end{array}$ \\
\hline 2. The banks ability to perform the promised service dependably and accurately. \\
3. The Coffee Shop's willingness to help customers and provide prompt service. \\
\hline 4. The knowledge and courtesy of the Coffee Shop's employees and their ability \\
to convey trust and confidence. \\
5. The caring, individual attention the Coffee Shop provides its customers.
\end{tabular}




\section{SIMPULAN}

Penelitian ini masih berjalan. Dengan harapan temuan baru yaitu program online feedback dari pelanggan ke perusahaan. Didalam pengisian suara pelanggan terdapat jabaran dari tabel 2. Servqual Importance Weight.

\section{DAFTAR PUSTAKA}

Parasuraman, e. a. (1998). SERVQUAL: a multi-item scale for measuring consumer perceptions of the service quality. Journal of Retailing, Vol. 64, No. 1, 12-40.

Fitzsimmons. (2011). Service Management: Operations, strategy, Information Technology.

Zeithaml, e. a. (1993). The Nature and Determinants of Customer Expectations of Service. Journal of the Academy of Marketing Science (hal. 21 (1), 1 - 12).

http://digilib.petra.ac.id/viewer.php?submit. $x=10 \&$ submit.y $=12 \&$ page $=6 \& q u a l=h i g h \&$ submitval=prev \&fname=\%2Fjiunkpe\%2Fs1\%2Fhotl\%2F2008\%2Fjiunkpe-ns-s1-2008-33403125-9845coffee_shop-chapter2.pdf

Ecimirnawati. (2010). Persepsi Konsumen Terhadap Suatu Produk. Web Blog bidang Pendidikan, diakses 8 Februari 2012 dari http://ecimirnawati.wordpress.com/2010/11/30/persepsikonsumen-terhadap-suatu-produk

http://www.emeraldinsight.com/content images/fig/0400170902001.png (gambar 1)

http://www.google.co.id/imgres?q=servqual+gap+model\&um=1\&hl=id\&client=firefox-

a\&rls=org.mozilla:en-

US:official\&biw=1280\&bih=885\&tbm=isch\&tbnid=4HaGOGuvzHnAmM:\&imgrefurl=http:// classes.bus.oregonstate.edu/ba302/reitsma/quality.html\&docid=yEuSXs43WT3MHM\&imgurl =http://classes.bus.oregonstate.edu/ba302/reitsma/images/service_gap_model.png\&w=1502\& $\underline{\mathrm{h}=789 \& \mathrm{ei}=\mathrm{uj0} 0-}$

T_6EFYXtrAey05TZBw\&zoom=1\&iact=rc\&dur=353\&sig=115655089132935883195\&page $=1 \&$ tbnh $=106 \&$ tbnw $=201 \&$ start $=0 \&$ ndsp $=20 \& v e d=0$ CHsQrQMwDw\&tx $=104 \& t y=50$ (gambar 2)

http://digilib.petra.ac.id/viewer.php?page $=1 \&$ submit. $x=0 \&$ submit. $y=0 \& q u a l=h i g h \&$ fname $=/$ jiunkpe/s 1/hotl/2008/jiunkpe-ns-s1-2008-33403125-9845-coffee_shop-chapter3.pdf 